\title{
O Enem nas pesquisas acadêmicas: saberes e práticas docentes em foco
}

\author{
Carla Alessandra de Oliveira Nascimento ${ }^{1}$ \\ Selva Guimarães ${ }^{2}$
}

\begin{abstract}
RESUMO
Este artigo apresenta resultados de uma pesquisa sobre a produção acadêmica no Brasil que tem como objeto o Enem e dialoga com teses que focalizam as implicações do Enem nos saberes e práticas de professores. Trata-se de um estado do conhecimento, por meio de levantamento, seleção, categorização e análise de teses produzidas nos programas de pós-graduação do país e publicizadas no Catálogo de Teses \& Dissertações da CAPES, no período de 2001 a 2018. Foram identificadas 147 teses em diferentes áreas, as quais foram organizadas em doze categorias. A análise do corpus, formado por 11 teses, evidenciou processos de aproximações, tensões, aceitação, críticas, resistências, deslocamentos de resistências, ampliação conceitual e influências diretas nos saberes e nas práticas docentes, mais pela motivação e demanda dos estudantes e da mídia do que pelos canais oficiais.
\end{abstract}

PALAVRAS-CHAVE: Enem. Estado do conhecimento. Professores. Saberes e práticas.

Enem in academic research: knowledge and teaching practices in focus

\begin{abstract}
This article presents the results of a research on academic production in Brazil, which has the object of Enem and dialogues with theses that focus
\end{abstract}

\footnotetext{
${ }^{1}$ Doutora em Educação. Programa de Pós-Graduação em Educação. Universidade Federal de Uberlândia, UberlândiaMG, Brasil. IFTM-Campus Uberaba, Uberaba, MG, Brasil. https://orcid.org/0000-0001-7662-1098. carlaalessandra@iftm.edu.br.

${ }^{2}$ Pós-Doutora em Educação. Programa de Pós-Graduação em Educação. Universidade de Uberaba, Uberlandia, MG, Brasil. https://orcid.org/0000-0002-8956-9564.selva.guimaraes@uniube.br .
} 
on the implications of Enem in the knowledge and practices of teachers. It is a state of knowledge, through the survey, selection, categorization and analysis of theses produced in the country's graduate programs and published in the CAPES Thesis \& Dissertations Catalog from 2001 to 2018. 147 theses were identified in different areas, which were organized into twelve categories. The analysis of the corpus formed by 11 theses showed processes of approximations, tensions, acceptance, criticism, resistance, displacement of resistance, conceptual expansion and direct influences on the knowledge and teaching practices, more for the motivation and demand of students and the media than for the channels. officers.

KEYWORDS: Enem. State of knowledge. Teachers. Knowledge and practices.

Enem en investigación académica: conocimiento y prácticas docentes en foco

\section{RESUMEN}

Este artículo presenta los resultados de una investigación sobre producción académica en Brasil que tiene el objeto de Enem y dialoga con tesis que se centran en las implicaciones de Enem en el conocimiento y las prácticas de los docentes. Es un estado de conocimiento, a través de levantamiento, selección, categorización y análisis de tesis producidas en los programas de posgrado del país y publicitadas en el Catálogo de Tesis y Disertaciones CAPES, en el periodo de 2001 a 2018. Se identificaron 147 tesis en diferentes áreas, que se organizaron en doce categorías. El análisis del corpus, formado por 11 tesis, mostró procesos de aproximaciones, tensiones, aceptación, críticas, resistencias, desplazamientos de resistencias, expansión conceptual e influencias directas sobre el conocimiento y las prácticas docentes, más por la motivación y demanda de los estudiantes y los medios de comunicación que por los canales oficiales.

PALABRAS ClAVE: Enem. Estado del conocimiento. Profesores. Conocimientos y prácticas. 


\section{Introdução}

No século XXI, houve significativa ampliação do Sistema Nacional da Pós-Graduação (SNPG) no Brasil. Conforme relatório da CAPES/MEC, entre os anos de 2013 a 2016, o número absoluto de programas cresceu de 3.337 para 4.175 , um aumento percentual de $25 \%$.(vinte e cinco por cento). ${ }^{3}$ Isso representa um avanço em termos de pesquisa e produção de conhecimento científico nas diferentes áreas. Outro indicador desse desenvolvimento foi relatado pela Associação Brasileira de Ciências, de acordo com uma pesquisa feita pela Clarivate Analytics, a pedido da CAPES, conforme Moura (2019). Os dados apurados indicam que o Brasil, no período de 2011-2016, publicou mais de 250.000 artigos na base de dados Web of Science em todas as áreas do conhecimento, o que corresponde à $13^{\mathrm{a}}$ posição na produção científica global, no ranking de 190 países. A pesquisa identificou as áreas de maior impacto e as instituições mais produtivas, sendo 95\%(noventa e cinco por cento) do trabalhos provenientes das universidades públicas ${ }^{4}$.

Nesse contexto, justificam-se os estudos denominados "estado da arte ou do conhecimento" para mapear a produção científica de determinadas áreas, inserida em tempo e lugar específicos, e identificar as configurações de um campo científico (BOURDIEU, 2004) e os lugares sociais de produção (BURKE, 2003), contribuindo, assim, para a história do conhecimento em Educação no século XXI. Esses estudos possibilitam reunir, distinguir publicações científicas, conforme categorias elencadas pelos investigadores que as realizam; identificar continuidades e descontinuidades; diagnosticar e analisar especificidades de um campo teórico, como recorrência e relevância de temas e objetos de pesquisa, metodologias, procedimentos e instrumentos de coleta e análise de dados, fundamentos teóricos, dentre outros aspectos.

\footnotetext{
${ }^{3}$ Fonte: https://sdi.capes.gov.br/banco-de-teses/02_bt_sobre.html. Acesso em 01/04/2019.

${ }^{4}$ Fonte:http://www.abc.org.br/2019/04/15/universidades-publicas-respondem-por-mais-de-95-da-producao-cientificado-brasil/ . Acesso em 01/04/2019.
} 
Em relação aos estados da arte e do conhecimento no campo da pesquisa em educação no Brasil, Ferreira (2002) emprega os dois termos como sinônimos. Morosini (2015, p. 102), utliza a nomenclatura "estado do conhecimento" congregando periódicos, teses, dissertações e livros sobre uma temática específica.

Por seu turno, Romanowski e Ens (2006, p. 39) salientam que, para caracterizar um estado da arte:

[...] não basta apenas estudar os resumos de dissertações e teses, são necessários estudos sobre as produções em congressos na área, estudos sobre as publicações em periódicos da área. O estudo que aborda apenas um setor das publicações sobre o tema estudado vem sendo denominado de 'estado do conhecimento'.

Neste trabalho, foi construído um inventário de pesquisas sobre o Exame Nacional do Ensino Médio (Enem) com o objetivo de dialogar com as teses que focalizam as implicações do Enem nos saberes e nas práticas docentes. Assim, de acordo com a distinção realizada por Romanowski e Ens (2006), o texto apresenta um estado do conhecimento das investigações acerca da referida temática, por meio da categorização das teses identificadas no Catálogo de Teses \& Dissertações da Capes e da revisão crítica dos trabalhos.

\section{O Enem nas pesquisas de Doutorado: a constituição do corpus}

A constituição de um corpus de pesquisa, segundo Bauer e Aartes (2010), compreende a escolha sistemática de algum material de pesquisa; a construção possibilita uma seleção qualitativa e "tipifica atributos desconhecidos" (2010, p. 40). Definido o tema e o problema, buscou-se constituir um corpus de maneira sistemática, fundamentado nos princípios da relevância, fidedignidade de "prestação de contas pública da pesquisa", defendido pelos autores.

Em sincronia com os objetivos, definiu-se como fonte o Catálogo digital da Coordenação de Aperfeiçoamento de Pessoal de Nível Superior 
(Capes), criado em 2002 e atualizado em 2013, quando passou a utilizar a tecnologia Elastic Search (ES) e Java. As informações bibliográficas das dissertações de mestrado e das teses de doutorado publicizadas são aquelas informadas anualmente à Capes pelos programas de pós-graduação de todo o país, que se responsabilizam pela veracidade dos dados. No Catálogo é possível realizar buscas valendo-se de diferentes filtros e/ou por todos eles, como: autor, título, instituição, tipo, nível e ano de defesa, orientador, resumo, palavras-chave, biblioteca, linha de pesquisa, área de conhecimento, programa, agência financiadora. Portanto, o Catálogo consitui uma ferramenta que torna público um retrato da produção acadêmica do país.

O corpus dessa investigação foi construído por meio do acesso à Plataforma Digital (catalogodeteses.gov.br) utilizando-se dois filtros: o termo (palavra-chave) "ENEM" e o tipo (grau acadêmico) "DOUTORADO". O recorte temporal foi de 2001 a 2018, pelo fato de o Exame ter sido criado em 1998, considerando que as teses são produzidas em um período entre três e quatro anos. O ano 2019 não foi incluído pelo fato de apresentar dados inconclusivos dos Programas de pós-graduação. Foram identificados 147 resultados/produtos/teses. O primeiro passo foi a seleção. Inicialmente, foi realizada uma leitura dos resumos e verificou-se que, algumas vezes, não era suficiente para estabelecer a relação entre a pesquisa em tela e o Enem. Passou-se a uma nova seleção e à leitura dos textos na íntegra, o que permitiu identificar de forma panorâmica, as teses em que o "Enem" perpassa o texto, de forma principal ou transversal, sem distinguir as áreas de conhecimento. Conforme se processava a leitura, era realizada a seleção e o agrupamento dos trabalhos que dialogavam entre si, no todo ou em parte, em categorias que focalizam o Exame na pesquisa em análise, como apresentado no Quadro1: 
Quadro 1 -Teses de Doutorado sobre o Enem - 2001 a 2018

\begin{tabular}{|l|l|c|}
\hline $\mathbf{N}$. & Categoria & Número de teses \\
\hline $\mathbf{1}$ & A acessibilidade ao Enem & 3 \\
\hline $\mathbf{2}$ & Estudos de questões/conteúdos do Enem & 16 \\
\hline $\mathbf{3}$ & $\begin{array}{l}\text { Impactos do Enem em temáticas diferentes dos saberes } \\
\text { e práticas dos professores }\end{array}$ & 11 \\
\hline $\mathbf{4}$ & $\begin{array}{l}\text { Impactos do Enem nos saberes e nas práticas de } \\
\text { professores }\end{array}$ & $\mathbf{1 1}$ \\
\hline $\mathbf{5}$ & Impactos sobre o Enem ${ }^{6}$ & 3 \\
\hline $\mathbf{6}$ & O Enem como mensurador de qualidade & 17 \\
\hline $\mathbf{7}$ & O Enem e a avaliação que realiza & 2 \\
\hline $\mathbf{8}$ & O Enem e as medidas de inteligência & 11 \\
\hline $\mathbf{9}$ & $\begin{array}{l}\text { O Enem e as políticas públicas de acesso ao ensino } \\
\text { superior }\end{array}$ & 1 \\
\hline $\mathbf{1 0}$ & $\begin{array}{l}\text { O Enem e as políticas públicas de certificação de jovens } \\
\text { e adultos }\end{array}$ & 1 \\
\hline $\mathbf{1 1}$ & O Enem e a liberdade de expressão & 13 \\
\hline $\mathbf{1 2}$ & O Enem e os currículos & 16 \\
\hline $\mathbf{1 3}$ & Representações midiáticas do Enem & 4 \\
\hline $\mathbf{1 4}$ & $\begin{array}{l}\text { Teses em que o Enem é citado, mas não é } \\
\text { problematizado }\end{array}$ & 5 \\
\hline $\mathbf{1 5}$ & Teses não localizadas & $\mathbf{1 4 7}$ \\
\hline $\mathbf{1 6}$ & Outras & 1 \\
\hline $\mathbf{T o t a l}$ & & 2 \\
\hline $\mathbf{F}$ & & 16 \\
\hline
\end{tabular}

Fonte: Elaboração e grifo das autoras, com base no Catálogo de Teses \& Dissertações/Capes (2020).

Verificou-se que, das teses localizadas na Plataforma sob a aplicação do filtro (palavra-chave) "Enem", cinco não abordam o Exame. Em 16 pesquisas, o Enem é citado, mas não há problematização sobre o tema. Em quatro teses, não foi possível localizar o resumo e o texto completo. Em síntese, contabilizou-se 122 teses que tratam do Enem como temática principal ou transversal. De acordo com as leituras, algumas teses podem ser alocadas em mais de uma categoria, de modo que as inserimos na categoria com as quais mais se relacionam.

A categoria que agrupou o maior número de investigações é a que denominamos "Estudos de questões/conteúdos do Enem", apresentada em 46 teses. Incluem-se nessa categoria os trabalhos com objetos de estudo

\footnotetext{
${ }^{5}$ Essa categoria se refere aos impactos sobre gestão escolar, livro didático, processos seletivos, avaliação de cursos, alunos, reestruturação curricular e matrículas nas escolas.

${ }^{6}$ Impactos de fatores socioeconômicos, atitudes e crenças de autoeficácia matemática (e dos salários dos professores) sobre o resultado do Enem.

${ }^{7}$ Constituição da avaliação: apectos psicométricos - Teoria de Resposta ao Item.
} 
diversos que contemplam análises das questões das provas, conteúdos e outros documentos do Enem. As categorias que reúnem menor número de trabalhos são "O Enem e as políticas públicas de certificação de jovens e adultos" e "Representações midiáticas do Enem", com uma investigação cada.

\section{Estado do conhecimento: uma análise de pesquisas sobre as implicações do Enem nos saberes e práticas docentes}

A seleção das teses que dialogam de forma estreita com o problema de estudo foram agrupadas em torno da categoria número quatro, denominada "Impactos do Enem nos saberes e nas práticas de professores". Esse conjunto foi dividido em dois grupos, respeitando o critério de área do conhecimento: Educação e outras áreas. O Quadro 2 apresenta trabalhos produzidos em programas de pós-graduação em Educação.

Quadro 2 - Teses relacionadas às implicações do Enem nos saberes e nas práticas docentes - Área de Educação

\begin{tabular}{|c|l|l|l|l|c|}
\hline N. & \multicolumn{1}{|c|}{ Título } & Autor(a) & Ano & Inst. & Área \\
\hline 1 & $\begin{array}{l}\text { A prática avaliativa } \\
\text { do Exame Nacional } \\
\text { do Ensino Médio } \\
\text { (ENEM): } \\
\text { pressupostos } \\
\text { conceituais e } \\
\text { implicações no } \\
\text { contexto escolar }\end{array}$ & $\begin{array}{l}\text { ZANCHET, } \\
\text { Beatriz } \\
\text { Maria } \\
\text { BoéssioAtrib }\end{array}$ & 2003 & Unisinos & Educação \\
\hline 2 & $\begin{array}{l}\text { Políticas públicas } \\
\text { de avaliação: o } \\
\text { Enem e a escola de } \\
\text { ensino médio }\end{array}$ & $\begin{array}{l}\text { Leila de } \\
\text { Almeida }\end{array}$ & 2005 & PUC/SP & Educação \\
\hline \multirow{2}{*}{$\begin{array}{l}\text { O ENEM e os } \\
\text { Professores de } \\
\text { Matemática do } \\
\text { Ensino Médio do } \\
\text { Paraná: } \\
\text { delineamento de } \\
\text { uma noção de } \\
\text { responsabilidade } \\
\text { curricular }\end{array}$} & $\begin{array}{l}\text { MELÃO, } \\
\text { Walderez } \\
\text { Soares }\end{array}$ & 2012 & UFPR & Educação \\
\hline
\end{tabular}




\begin{tabular}{|c|l|l|l|l|l|}
\hline 4 & $\begin{array}{l}\text { Política de } \\
\text { avaliação e trabalho } \\
\text { docente no ensino } \\
\text { médio }\end{array}$ & $\begin{array}{l}\text { CARNEIRO, } \\
\text { Veronica } \\
\text { Lima }\end{array}$ & 2013 & UFPA & Educação \\
\hline 5 & $\begin{array}{l}\text { O Exame Nacional } \\
\text { do Ensino Médio: } \\
\text { reconstruída por } \\
\text { professores de uma } \\
\text { escola pública } \\
\text { paulista }\end{array}$ & $\begin{array}{l}\text { Juliana } \\
\text { Cristina } \\
\text { Perlotti }\end{array}$ & 2015 & UFSCar & Educação \\
\hline \multirow{2}{*}{$\begin{array}{l}\text { Gênese e } \\
\text { materialidade da } \\
\text { noção de } \\
\text { competências na } \\
\text { prática pedagógica } \\
\text { de professores de } \\
\text { uma escola de } \\
\text { ensino médio em } \\
\text { Macapá/AP }\end{array}$} & $\begin{array}{l}\text { ALVES, } \\
\text { João Paulo } \\
\text { da }\end{array}$ & 2015 & UFPA & Educação \\
\hline
\end{tabular}

Fonte: Elaboração das autoras, com base no Catálogo de Teses \& Dissertações/Capes (2020).

Em consonância com o Quadro 2, o maior número de teses, neste grupo, foi produzido após a implantação do Novo Enem no ano 2009. A partir desse ano, os participantes passaram a usar a nota obtida para o acesso ao ensino superior nas universidades públicas por meio do SISUSistema de Seleção Unificada, uma plataforma digital desenvolvida pelo MEC e implementada desde janeiro de 2010.

Duas pesquisas sobre "Impactos do Enem nos saberes e nas práticas de professores" foram aprovadas antes da implantação do Novo Enem: Zanchet (2003) e Locco (2005). Zanchet (2003) investigou a centralidade da avaliação nas políticas educacionais no Brasil e como as avaliações de desempenho dos alunos e o currículo limitam a autonomia dos professores, uma vez que direcionam e interferem no trabalho docente. Abordou o Enem, naquele momento histórico, como exame de caráter voluntário, realizado por estudantes concluintes ou egressos do ensino médio para, de acordo com documentos referentes ao Exame, avaliar o desempenho dos alunos ao final da educação básica. 
A metodologia usada foi pautada na abordagem qualitativa, cujos procedimentos de coleta envolveram análise de documentos e entrevista semiestruturada. A análise dos dados contou com os referenciais da Análise de Conteúdo (AC). A pesquisa empírica de Zanchet (2003) foi realizada com 12 professores atuantes no ensino médio, das redes particular e pública estadual e municipal, de áreas de formação diversas. O estudo buscou captar as concepções dos docentes sobre a implantação da proposta de desenvolvimento de competências; as políticas governamentais de avaliação para o ensino médio e o Enem; e a repercussão desses elementos na prática pedagógica.

Os principais resultados encontrados por Zanchet (2003) foram: na visão dos docentes investigados, o Enem era a forma utilizada pelo governo para diagnosticar o ensino médio no Brasil; nas escolas, não havia discussão sobre os pressupostos conceituais do Exame e sua implantação; o Enem provocou um leve deslocamento das questões focadas nos conteúdos para as que se voltam às competências; os professores consideravam importante que os educandos participassem do certame e os incentivavam; os docentes, a partir das provocações dos alunos, preocupavam-se com a resolução de questões das provas do Enem; houve um redirecionamento das práticas pedagógicas; na concepção dos professores, prevaleceu a ênfase no ensino médio preparatório para o ensino superior; evidenciou o reconhecimento da necessidade de boa formação docente em relação aos conteúdos específicos e a constação da carência de saberes para a resolução de problemas decorrentes da prática pedagógica.

Locco (2005) investigou a política de avaliação do Enem e, como finalidade, propôs detectar e dimensionar suas repercussões na educação básica, sobretudo em instituições de ensino médio. Adotou a abordagem qualitativa e realizou uma pesquisa de campo em duas escolas da rede pública estadual em Curitiba/PR. A coleta de dados foi realizada por meio da aplicação de um questionário a professores, gestores e alunos, ao final do ensino médio. 
Locco (2005) evidenciou a importância do currículo para avaliações externas como o Enem e ressaltou a noção de competência como aspecto definidor. Colocou em questão a implantação do Exame sob a base de competências, em 1998, ao mesmo tempo em que as próprias competências estavam sendo postas nas Diretrizes Curriculares Nacionais para o Ensino Médio (1998) e nos Parâmetros Curriculares Nacionais para o Ensino Médio (1999/2000). A autora criticou a inexistência de registros de participação efetiva de gestores e professores das escolas na elaboração das políticas de avaliação. Outra constatação foi a aceitação do Enem por organismos educacionais e seus sujeitos, mídia e sociedade, em que se sobressaiu o caráter voluntário do Exame e sua adoção por algumas IES como componente do processo seletivo para o acesso ao ensino superior.

Da pesquisa empírica realizada com alunos, professores (que abordamos aqui) e gestores das escolas eleitas, Locco (2005) demonstrou que no entendimento dos professores uma das finalidades do Enem era "testar" ou "verificar" se os alunos estavam preparados para o vestibular; os docentes viam o Enem como instrumento diagnóstico, tanto para os estudantes como para o sistema, o que pode levar ao controle e à regulação do ensino médio. Segundo a autora, havia certa resistência dos professores em relação ao certame, faltava discussão a respeito das políticas de avaliação e inexistia um canal de comunicação entre as escolas e o Inep. Outro aspecto apontado pelos professores investigados foi a expectativa proporcionada pelo Enem em relação à conquista da vaga no ensino superior pelos alunos da escola pública, além de "preparar para" o vestibular. Os docentes declararam que não realizavam a preparação dos estudantes para o Exame, mas seguiam o livro didático, que tem trazido questões das provas. (LOCCO, 2005).

Dentre as teses aprovadas após a mudança do Enem, a investigação de Melão (2012) teve o objetivo de conhecer o tipo de repercussão provocada pelo Enem no trabalho do professor de Matemática do ensino médio, além de identificar as relações com a Matriz de Referência do Enem (INEP, 2009) e as diretrizes curriculares do ensino médio. O levantamento de dados foi realizado por meio de questionário enviado no formato Google Docs aos 
professores de Matemática do Paraná, dos quais obteve 251 respostas. A investigação evidenciou que, em relação aos conteúdos, grande parte dos professores colaboradores indicou que o Enem tem influência benéfica no trabalho em sala, por ser direcionado aos assuntos que caem na prova; e que a Matriz de Referência (INEP, 2009) contempla parcialmente os conteúdos do ensino médio.

A maior parte dos professores colaboradores da investigação de Melão (2012) indicou a importância da preparação dos alunos para o Enem; alguns entendiam que as atividades preparatórias fazem parte do programa; outros informaram que elas devem ser realizadas, mesmo que comprometam o planejamento; e houve aqueles para os quais a preparação deve ser realizada fora do programa. Ainda que em menor percentual, houve uma parcela de colaboradores (11\%) que não preparava os alunos para o Exame, o que leva a entender que a prática pedagógica desses profissionais não era influenciada (ou era menos influenciada) pelo Enem.

Melão (2012) explicitou o processo de esvaziamento dos currículos da escola básica, em razão de as matrizes curriculares das avaliações de larga escala não contemplarem conteúdos das diretrizes curriculares vigentes. Criticou a homogeneização curricular decorrente das políticas de currículo nacional, como a Matriz de Referência do Enem (INEP, 2009). Para a autora, a homogeneização pode apagar as diferenças necessárias para o estabelecimento de currículos nacionais, sob a égide de um currículo geral, balizador dos saberes a serem ensinados no país.

Por sua vez, Carneiro (2013) adotou a abordagem qualitativa, com foco nas políticas de avaliação externa, em especial as que se referem ao Novo Enem e suas repercussões no trabalho docente. A pesquisa empírica ocorreu em três instituições estaduais da região metropolitana de Cariri/CE: a escola com maior pontuação no Enem de 2009, a de menor pontuação e outra com desempenho mediano. Além da revisão bibliográfica, o estudo contou com análise documental e entrevistas não diretivas. As entrevistas foram realizadas com 12 professores de disciplinas diversas que 
contemplavam as quatro áreas avaliadas pelo Enem, e a $\mathrm{AC}$ embasou a análise dos dados.

Carneiro (2013, p. 229) constatou repercussões do Enem sobre o trabalho do professor e as caracterizou como "extremamente significativas e preocupantes". A autora destacou a pressão do Exame por resultados quantitativos e a intensificação do trabalho docente. Carneiro (2013) evidenciou que a maioria dos professores investigados era favorável ao Enem enquanto meio democrático de acesso ao ensino superior. A minoria expôs a retirada da autonomia e do tempo livre dedicado ao lazer e à família como consequências do Exame. Alguns questionaram a aplicação de um teste padronizado em um contexto bastante diversificado, e grande parte não estabeleceu relações entre a situação laboral e a política educacional desenvolvida.

Alves (2015) pesquisou a influência da Pedagogia das Competências sobre a prática pedagógica de professores do ensino médio. Trata-se de um estudo de caso desenvolvido em uma escola pública estadual de ensino médio, na cidade de Macapá/AP. O instrumento de coleta de dados foi a entrevista semiestruturada realizada com oito professores, além da análise de documentos pedagógicos da escola e da Secretaria de Estado da Educação do Amapá (SEED/AP). O referencial de análise foi a AC.

Alves (2015) verificou que o Enem foi contemplado em todas as categorias: planejamento - apesar de não mencionar o Exame, o plano de curso da escola prioriza conteúdos recomendados para a preparação para o Enem e os vestibulares; finalidades - indicam a preparação dos alunos para estudos posteriores e o ensino superior, autorregulados pelo Enem; conteúdos - são materializados no cotidiano das aulas e em projetos pedagógicos considerados fundamentais para a preparação dos estudantes; metodologia - foi marcada por ações individualizadas e inovações, tendo a centralidade do Enem como uma das categorias empíricas construídas. Assim, pode-se observar que, na pesquisa de Alves (2015), o Enem é utilizado como referência para o desenvolvimento das ações pedagógicas. 
Alves (2015) observou uma correspondência parcial entre a prática pedagógica dos professores da escola investigada e o Enem, em razão de o planejamento ser individualizado e o conhecimento, compartimentado em disciplinas. Mesmo assim, concluiu que a relação entre a base curricular da instituição de ensino e os conteúdos programáticos do Enem promove aproximação entre a prática docente e a Pedagogia das Competências.

A investigação de Piunti (2015, p. 21) teve como objetivo "compreender a perspectiva de professores do ensino médio sobre as repercussões do Enem em suas práticas profissionais docentes". Adotou a abordagem qualitativa e elegeu, como lugar da pesquisa, uma escola da rede pública estadual paulista, localizada em Sumaré/SP. Os dados foram coletados em 2012, por meio de entrevistas com cinco professores, os quais contemplaram as quatro áreas definidas pelo Exame, e uma coordenadora. Por um período de quatro meses, enquanto realizava reuniões com a equipe gestora ou visitas, a pesquisadora desenvolveu a técnica de observação na escola e formalizou um diário de campo. Em 2014, houve um reencontro entre ela e os docentes, incluindo outros além dos entrevistados - essa etapa foi registrada em diário de campo. Para a análise dos dados, recorreu à AC e sua "subtécnica"8 de Análise Temática.

Os resultados da investigação de Piunti (2015) mostraram que a relação dos professores colaboradores com o Enem envolve contradições: os docentes desconheciam os documentos oficiais e o ensino médio não foi contemplado com uma identidade definida. Entretanto, verificou que o Exame pode imprimir significado à prática docente, além de gerar expectativas nos alunos que, por seu turno, sensibilizavam e mobilizavam os professores. Outra contradição apontada é que, apesar de o Enem contribuir para as transformações no currículo e com a demora pela concepção de uma identidade para o ensino médio, o Exame tem gerado questionamento das práticas docentes. 
Para a referida autora, o Enem não transformou a escola como um todo, mas produziu um efeito motivador. Concluiu que, apesar das contradições, do contexto adverso e do isolamento nas práticas docentes, os professores se desenvolveram, pois buscaram alternativas coletivas no que tange às práticas de ensino e criaram expectativas nos alunos.

Em concordância com Piunti (2015) e as pesquisas supramencionadas, verifica-se a importância da problematização do Enem nas formações inicial e permanente do professor, além da necessidade de ouvir os docentes. Como observado nos delineamentos metodológicos das teses, em todas as investigações, os professores e/ou gestores e estudantes foram sujeitos colaboradores ativos e demonstraram suas visões, demandas e críticas ao Enem como política educacional que afeta diretamente a Educação Básica.

O segundo conjunto de teses, apresentado no Quadro 3, foram produzidas em programas de pós-graduação em outras áreas do conhecimento.

Quadro 3-Teses relacionadas às implicações do Enem nos saberes e nas práticas docentes - Outras áreas

\begin{tabular}{|c|l|l|c|c|c|}
\hline N. & \multicolumn{1}{|c|}{ Título } & \multicolumn{1}{|c|}{ Autor(a) } & Ano & Instituição & Área \\
\hline 1 & $\begin{array}{l}\text { A avaliação sob duas } \\
\text { lógicas: Um enfoque no } \\
\text { ensino de física no } \\
\text { município de campos } \\
\text { dos Goytacazes-RJ. }\end{array}$ & $\begin{array}{l}\text { PEIXOTO, } \\
\text { Karla } \\
\text { Cynthia } \\
\text { Quintanilha }\end{array}$ & 2012 & UENF & $\begin{array}{c}\text { Ciências } \\
\text { Naturais }\end{array}$ \\
\hline $\begin{array}{l}\text { Enem e ensino de } \\
\text { Geografia: o } \\
\text { entendimento dos } \\
\text { professores e gestores } \\
\text { da rede pública } \\
\text { estadual em relação ao } \\
\text { Exame Nacional do } \\
\text { Ensino Médio e a } \\
\text { melhoria da educação } \\
\text { básica }\end{array}$ & $\begin{array}{l}\text { MARÇAL, } \\
\text { Menha da } \\
\text { Vieira }\end{array}$ & 2014 & UFU & Geografia \\
\hline 3 & $\begin{array}{l}\text { O Inglês no ENEM e na } \\
\text { escola: práticas de dois } \\
\text { professores do ensino } \\
\text { médio }\end{array}$ & $\begin{array}{l}\text { AVELAR, } \\
\text { Flavia } \\
\text { Juliana de } \\
\text { Sousa }\end{array}$ & 2015 & UNICAMP & $\begin{array}{l}\text { Linguística } \\
\text { Aplicada }\end{array}$ \\
\hline
\end{tabular}




\begin{tabular}{|c|c|c|c|c|c|}
\hline 4 & $\begin{array}{l}\text { O ENEM e a política } \\
\text { linguística para o } \\
\text { Inglês no Brasil: da } \\
\text { legislação às } \\
\text { representações de } \\
\text { coordenadores, } \\
\text { professores e alunos em } \\
\text { um contexto de ensino }\end{array}$ & $\begin{array}{l}\text { OLIVEIRA, } \\
\text { Andrea } \\
\text { Barros } \\
\text { Carvalho de }\end{array}$ & 2017 & UNICAMP & $\begin{array}{c}\text { Linguística } \\
\text { Aplicada }\end{array}$ \\
\hline 5 & $\begin{array}{l}\text { Políticas linguísticas e } \\
\text { impacto: a língua } \\
\text { estrangeira no Enem }\end{array}$ & $\begin{array}{l}\text { BLANCO, } \\
\text { Juliana }\end{array}$ & 2018 & UFSCar & Linguística \\
\hline
\end{tabular}

Fonte: Elaboração das autoras, com base no Catálogo de Teses \& Dissertações/Capes (2020).

O estudo de Peixoto (2012) objetivou "[...] explorar e interpretar acordos e conflitos existentes entre a avaliação da aprendizagem e a avaliação em larga escala em escolas públicas do município de Campos dos Goytacazes/RJ" (PEIXOTO, 2012, p.16).

Nesse sentido, Peixoto (2012) adotou a abordagem qualitativa, em que a pesquisa empírica foi realizada com 11 professores licenciados em Física e que ministraram essa disciplina em 2010; e com 189 estudantes do $3^{\circ}$ ano do ensino médio - sendo 87 pré-Enem e 102 pós-Enem - nas escolas onde atuavam os professores colaboradores. A coleta de dados usou como instrumentos o questionário, aplicado a professores e alunos, além da entrevista semiestruturada com quatro professores. Além disso, analisou questões de Ciências da Natureza das edições do Enem de 2009, 2010 e 2011, que abordaram conceitos de Física. Os dados foram analisados por meio da Análise Textual Discursiva (ATD).

Peixoto (2012) explicitou que o Enem não causou impactos expressivos na prática docente. Alguns fatores corroboraram os resultados encontrados: incompatibilidade do currículo e dos materiais didáticos com o Exame; falta de incentivo ou motivação em relação ao Enem; exigência do alcance de outros índices por parte do governo estadual, com recompensa para os alunos e a escola; falta de infraestrutura e laboratórios; dentre outros. Apesar das dificuldades apresentadas por docentes, discutiu-se a valorização do Enem no contexto escolar e sua contribuição para a 
aprendizagem dos alunos e a formação de pessoas mais críticas e reflexivas. Além disso, reconheceu a necessidade de equilíbrio em relação aos conteúdos do certame, para que não repitam os vestibulares e se tornem predominantemente disciplinares em um exame que visa primar por contextualização e interdisciplinaridade, além de atuar como meio de acesso ao ensino superior.

Marçal (2014) investigou a repercussão do Enem na forma de ensinar dos professores de Geografia do ensino médio e na organização das escolas estaduais de Patos de Minas/MG. Nove diretores, 10 escolas e 25 professores participaram da pesquisa. $\mathrm{O}$ estudo, de abordagem quanti-qualitativa, teve como instrumentos de coleta de dados as entrevistas semiestruturadas com os gestores e o questionário para os professores. Para a análise, empregou-se o coeficiente de correlação Spearman ${ }^{9}$ e a AC.

A autora destacou a falta de debates sobre as avaliações em larga escala e a pressão que têm sofrido professores e gestores em virtude da divulgação do ranqueamento dos resultados, o que contribui para alterar o foco do trabalho pedagógico. Marçal (2014) atribuiu o delineamento mercantil e neoliberal a essa prática, além da adoção da avaliação como forma de regular o ensino, sendo a função e a qualidade definidas por agências financiadoras da educação.

A pesquisa identificou que os currículos são definidos pelas avaliações externas, uma vez que, ao se sentirem pressionados, os docentes engendram ações que levam a alcançar bons resultados; associa-se o currículo de trabalho aos pressupostos das avaliações, inclusive do Enem. Concluiu-se que o Exame é um indicativo das reformulações curriculares sinalizadas nos documentos oficiais. A vinculação currículo/avaliação pode ser constatada na BNCC - Base Nacional Comum Curricular em vigor no Brasil, desde 2017, analisada por diferentes autores em Ensino em Re-Vista (2018).

\footnotetext{
${ }^{9}$ De acordo com Marçal (2013, p.34), “essa correlação é uma medida limitada entre -1 e +1 , sendo que quanto mais próximo o coeficiente estiver de -1 , maior a correlação negativa e quanto mais próximo o coeficiente estiver de +1 , maior a correlação positiva. Uma correlação negativa significa que, se uma variável aumentar, a outra tende a diminuir, enquanto uma correlação positiva significa que, se uma variável aumentar, a outra variável também tende a aumentar".
} 
Por parte dos professores, Marçal (2014) constatou o reconhecimento de que o Enem é encaminhado como único meio de acesso dos alunos das escolas públicas à universidade. Entretanto, questiona-se o caráter democrático, uma vez que as instituições particulares preparam os estudantes de forma cada vez mais incisiva para o Exame, algo que não acontece na rede estadual. Os gestores declararam que há preocupação tanto da gestão como dos professores em alcançar bons resultados no Enem e há um aumento significativo das atividades docentes em razão dessa realidade. Apesar disso, os resultados demonstraram que a maioria dos professores colaboradores não conhecia a Matriz de Referência do Enem (INEP, 2009), tampouco seus pressupostos políticos, o que pode indicar que o conhecimento deles sobre o certame tem origem, principalmente, na mídia.

Marçal (2014) destacou ainda que há tentativas de mudanças em relação ao Enem, mas, na prática pedagógica, elas ocorrem de forma lenta, sem delineamento. Existem algumas iniciativas dos professores colaboradores para modificar as estratégias de ensino, mas se apresentam de forma superficial no sentido de prepará-los para a prova do Enem, e em eventos esporádicos, o que, no entendimento da autora, não se caracteriza como ações pedagógicas de melhoria do processo de ensino e aprendizagem.

Avelar (2015, p. 16) investigou os "efeitos que a prova de Inglês do ENEM pode exercer sobre as ações de professores de Inglês no ensino médio". Com base, principalmente, no efeito retroativo, questionou se a prova de Inglês do Enem tem força suficiente para causar efeitos retroativos desejados no ensino do idioma. Adotou uma abordagem qualitativa de cunho etnográfico e usou, como procedimentos de coleta, a entrevista semiestruturada e as conversas informais realizadas com dois professores de Inglês e dois coordenadores; a observação em sala de aula gravada em áudio e registrada em diário de campo; o questionário aplicado aos alunos do segundo e terceiro anos do ensino médio; o material didático adotado; e as avaliações de rendimento. A investigação foi realizada em duas escolas regulares na região metropolitana de Campinas-SP - uma pública e outra particular. 
Quanto à escola pública, Avelar (2015) destacou que o efeito retroativo da prova de Inglês do Enem ficou evidenciado no Caderno de Inglês elaborado e distribuído pelo estado de São Paulo. Os docentes não compreendem o Enem como meio de acesso à universidade, e as provas do Sistema de Avaliação de Rendimento Escolar do Estado de São Paulo (SARESP) constituem o foco da atenção e, consequentemente, da prática dos professores. Esse exame apresenta baixa relevância para os alunos, porque os resultados não refletem mudanças ou tomadas de decisões para eles. Contudo, apresenta alta imprescindibilidade para professores e administração escolar, pois influencia na distribuição de recursos financeiros para as escolas e bônus para docentes e gestores.

Em relação à escola particular, Avelar (2015) afirmou que não há influência significativa da prova de Inglês do Enem na prática dos professores, e as aulas são direcionadas aos vestibulares. No Exame, ela é considerada fácil pelos professores e sua importância é minimizada frente ao quantitativo das questões das outras áreas, uma vez que há apenas cinco de Inglês. Assim, os docentes entendem que se os alunos estiverem preparados para as provas de Língua Inglesa dos vestibulares estarão também preparados para o Enem.

Oliveira (2017) pesquisou sobre a política linguística para o Inglês como língua estrangeira no Brasil e as implicações da inclusão desse idioma no Enem, a partir de documentos oficiais e das representações dos sujeitos integrantes de um contexto de ensino. Trata-se de uma investigação qualitativa/interpretativista, cuja coleta de dados envolveu análise documental (provas de Inglês do Enem e legislação sobre o ensino de Língua Inglesa) e entrevistas semiestruturadas realizadas com dois professores da disciplina, dois coordenadores da área na rede pública de ensino e 18 estudantes de um curso preparatório gratuito para vestibulares, ofertado como projeto socioeducativo. O estudo ocorreu em São Roque/SP.

Oliveira (2017) partiu do pressuposto de que a presença do referido idioma no Enem causaria mudanças nas representações e atitudes dos sujeitos envolvidos no processo educativo, aumentando a importância 
atribuída ao Inglês como língua estrangeira. Essa hipótese não foi confirmada: no discurso de professores e alunos, o Enem configurou-se como elemento importante para a vida acadêmica dos estudantes, mas a prova de Inglês não é priorizada, sobretudo pela baixa dificuldade das questões e pela reduzida quantidade de questões no Exame (cinco questões).

A autora destacou as vozes dos professores em relação à influência que políticas educacionais regionais exercem para que os conteúdos a serem desenvolvidos sejam restritos ao material disponibilizado pela Secretaria de Educação do Estado de São Paulo, o que interfere no impacto do Enem (ou na falta dele) nas práticas em sala de aula.

A investigação de Blanco (2018) abordou as políticas linguísticas que fundamentam e justificam as provas de língua estrangeira (inglês e espanhol) do Enem e o impacto das provas nas crenças e nas práticas dos alunos e das professoras. O cenário de pesquisa foi uma escola municipal do estado de São Paulo, localizada na capital. Os sujeitos foram 34 alunos e duas professoras do último ano do ensino médio das disciplinas espanhol e inglês. A autora problematizou o Enem como mecanismo implícito de política linguística e buscou efeitos retroativos do Exame nas práticas de professores de língua estrangeira.

Blanco (2018) constatou que não houve impacto retroativo do Enem na prática da professora de Inglês, pois ela não abordou o Exame em suas aulas. Em relação à prática da professora de Espanhol, Blanco (2018) afirmou a existência do referido efeito: a professora comentava sobre o Enem com os alunos, resolvia questões da prova e motivava os alunos a participarem do Exame. Enfim, a autora reconheceu que, muitas vezes, tanto os exames como o ensino de línguas estrangeiras são determinados mais por interesses políticos do que linguísticos.

\section{Considerações finais}

As investigações analisadas demonstram que o Enem, criado fora da escola, executado fora da escola, tornou-se parte da escola de ensino médio. 
O diálogo com as leituras permite-nos depreender que o Exame abrange vertentes educacionais relevantes, como a avaliação, o currículo, os saberes e as práticas docentes, dentre outras.

As teses analisadas foram produzidas em diferentes estados do Brasil. Nota-se que as pesquisas realizadas no estado de São Paulo evidenciam um maior distanciamento de professores e alunos em relação ao Enem. O foco recai na Avaliação do Estado e nos vestibulares. Todas as pesquisas situamse no campo qualitativo e por meio de diferentes instrumentos registraram as "vozes" de professores e alunos.

As teses revelam o fato de que a maioria dos sujeitos escolares não foi convidada a participar dos debates para elaboração, implantação e implementação do Enem como política pública, o que pode ter gerado consequências advindas do sentimento de não pertencimento desses atores no desenvolvimento dos processos.

Segundo Ball e Bowe (1992), as vozes dos profissionais são importantes para a implementação das políticas públicas. É nesse momento que os textos políticos são interpretados, reinterpretados de diferentes maneiras, por diferentes pessoas, com suas histórias de vida e experiências. É nesse contexto que a política pública é recriada. Tal situação influenciou na construção do Enem como política pública para o desenvolvimento do ensino médio e na interpretação do caráter avaliativo do Enem, desconsiderando-se seu potencial no desenvolvimento da qualidade do ensino médio.

Assim, ocorreu quanto às relações Enem-currículo e Enemcompetências e habilidades. Ao realizarem a leitura da Matriz de Competências e, posteriormente, de Referências do Enem, muitos profissionais as interpretaram como um guia curricular e de conteúdos já finalizado. Esse entendimento faz com que a matriz seja vista como diretriz limitadora do conhecimento. A recepção dos documentos sem espaço de discussão dificultou a compreensão acerca da possibilidade de construção e ampliação curricular. Faltavam informações e canais para obtê-las, e, nos 
isolados contextos de prática, parte dos docentes desconhecia ou conhecia superficialmente o Enem.

Todavia, essa realidade foi em parte modificada com o decorrer do tempo. Houve deslocamentos na resistência e aceitação dos professores em relação ao Enem, além de sua ampliação conceitual, que perpassa desde a avaliação externa da educação até o mecanismo de acesso ao ensino superior. Há uma crítica sobre a "retirada" da autonomia docente e a homogeneização curricular pela Matriz do Enem. Observaram-se impactos do Exame nos saberes e nas práticas dos professores, porém mais influenciados pela necessidade/motivação dos estudantes e pela mídia do que pelos canais oficiais. Sublinha-se este achado: o Enem como elemento motivador dos estudantes.

Os estudos realizados indicam que, enquanto política pública de educação, o Enem ainda não alcançou seu amplo potencial pedagógico, com vistas a produzir impactos significativos na qualidade da educação básica. No entanto, constitui uma política que ainda está em curso; logo, não é possível determinar e concluir sobre seu alcance final ou pleno.

Nesse ínterim, as atuais transformações no contexto educacional brasileiro intensificam o debate a respeito das vertentes político-ideológicas que permeiam o ensino médio. Há um discurso recorrente e uma suspeita entre os pesquisadores e educadores de que, no Brasil, as políticas públicas de educação, muitas vezes, são modificadas, sem levar em consideração os dados das pesquisas e as demandas da sociedade, visando às propostas de governos, acompanhando as concepções ideológicas dos representantes eleitos. Nesse cenário, a Reforma do Ensino Médio (2015) e a aprovação da Base Nacional Comum Curricular (2015-2016) e as políticas educacionais do governo federal conservador (2019-2022) podem, em um futuro próximo, produzir outras reconfigurações do Enem. 


\section{Referências}

ALVES, J. P.C. Gênese e materialidade da noção de competências na prática pedagógica de professores de uma escola de ensino médio em Macapá/AP. 2015. Tese (Doutorado em Educação)- Universidade Federal do Pará, Belém, 2015.

AVELAR, F. J. S. O Inglês no ENEM e na escola: práticas de dois professores do ensino médio. 263f. 2015. Tese (Doutorado em Linguística Aplicada)- Universidade Estadual de Campinas, Campinas, 2015.

BAUER, M. W.; AARTS, B. A construção do corpus: um princípio para a coleta de dados qualitativos. In: BAUER, Martin, W; GASKELL, George (Org.). Pesquisa qualitativa com texto, imagem e som. Petrópolis: Vozes, p. 39-63, 2002.

BALL, S. J.; BOWE, R. Subject departments and the "implementation" of National Curriculum policy: an overview of the issues. Journal of Curriculum. DOI: https://doi.org/10.1080/0022027920240201.

BLANCO, J. Políticas linguísticas e impacto: a língua estrangeira no Enem. $223 \mathrm{f}$. 2018. Tese (Doutorado em Linguística) - Universidade Federal de São Carlos, São Carlos, 2018.

BORDIEU, P. Os usos sociais da Ciência: por uma sociologia clínica do campo científico. São Paulo: UNESP, 2004.

BURKE, P. Uma história social do conhecimento. De Gutenberg a Diderot. Rio de Janeiro: Jorge Zahar Editora, 2003.

CAPES. Coordenação de Aperfeiçoamento de Pessoal de Nível Superior. Catálogo de teses. [s.d.]. Disponível em: https://catalogodeteses.capes.gov.br/catalogo-teses/\#!/ e https://sdi.capes.gov.br/banco-de-teses/02_bt_sobre.html . Acesso em: 01/04/2020.

CARNEIRO, V. L. Política de avaliação e trabalho docente no ensino médio. 258f.2013. Tese (Doutorado em Educação)- Universidade Federal do Pará. Instituto de Ciências da Educação, Belém, 2013.

ENSINO EM RE-VISTA. Dossiê BNCC. Diferentes olhares, Volume 25 - Número Especial - dezembro de 2018. Disponível em http://www.seer.ufu.br/index.php/emrevista/issue/view/1770. Acesso em 01/04/2020.

FERREIRA, N. S. A. As pesquisas denominadas "estado da arte". Educação \& Sociedade, Campinas, ano 23, n. 79, p. 257-272, ago. 2002. DOI:

https://doi.org/10.1590/S0101-73302002000300013.

LOCCO, L. A. Políticas públicas de avaliação: o Enem e o ensino médio. 141f. 2005. Tese (Doutorado em Educação) - Pontifícia Universidade Católica, São Paulo, 2005.

MARÇAL, M. P. V. Enem e ensino de Geografia: o entendimento dos professores e gestores da rede pública estadual em relação ao exame nacional do ensino médio e 
a melhoria da educação básica. 226 f. 2014. Tese (Doutorado em Geografia) Universidade Federal de Uberlândia, Uberlândia, 2014.

MELÃO, W. S. O Enem e os professores de matemática do ensino médio do Paraná:delineamentode uma noção de responsabilidade curricular. 111f. 2012. Tese (Doutorado em Educação) - Universidade Federal do Paraná, Curitiba, 2012.

MOROSINI, M. C. Estado de conhecimento e questões do campo científico. Educação, Santa Maria, v. 40, n. 1, p. 101-116, jan./abr. 2015. DOI: https://doi.org/10.5902/1984644415822

MOURA, M. Universidades públicas respondem por mais de $95 \%$ da produção científica do Brasil. Ciência na Rua, abr. 2019. In: Academia Brasileira de Ciências. Disponível em: http://www.abc.org.br/2019/04/15/universidades-publicasrespondem-por-mais-de-95-da-producao-cientifica-do-brasil/. Data do acesso: 01/04/2020.

OLIVEIRA, A. B. C. O ENEM e a política linguística para o inglês no Brasil: da legislação às representações de coordenadores, professores e alunos em um contexto de ensino. 247f. 2017. Tese (Doutorado em Linguística Aplicada) - Universidade Estadual de Campinas, Campinas, 2017.

PEIXOTO, K. C. Q. C. A avaliação sob duas lógicas: um enfoque no ensino de física no município de Campos dos Goytacazes/RJ. 181f. 2012. Tese (Doutorado em Ciências Naturais) - Universidade Estadual do Norte Fluminense Darcy Ribeiro, Campos dos Goytacazes, 2012.

PIUNTI, J. C. P. O Exame Nacional do Ensino Médio: uma política reconstruída por professores de uma escola pública paulista. 2015. Tese (Doutorado em Educação) - Universidade Federal de São Carlos, São Carlos, 2015.

ROMANOWSKI, J. P.; ENS, R. T. As pesquisas denominadas do tipo "estado da arte” em educação. Diálogo Educacional, Curitiba, v. 6, n.19, p.37-50, set./dez. 2006.

ZANCHET, B. M. B. A. A prática avaliativa do exame nacional do ensino médio (Enem): pressupostos conceituais e implicações no contexto escolar. 303f. 2003. Tese (Doutorado em Educação) - Universidade do Vale do Rio dos Sinos, São Leopoldo, 2003. 